\title{
p66SHC promotes T cell apoptosis by inducing mitochondrial dysfunction and impaired $\mathrm{Ca}^{2+}$ homeostasis
}

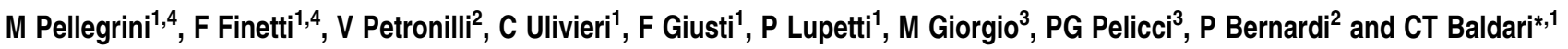

p66Shc, a redox enzyme that enhances reactive oxygen species (ROS) production by mitochondria, promotes T cell apoptosis. We have addressed the mechanisms regulating p66Shc-dependent apoptosis in T cells exposed to supraphysiological increases in $\left[\mathrm{Ca}^{2+}\right]_{\mathrm{c}}$. p66Shc expression resulted in profound mitochondrial dysfunction in response to the $\mathrm{Ca}^{2+}$ ionophore $\mathrm{A23187}$, as revealed by dissipation of mitochondrial transmembrane potential, cytochrome $c$ release and decreased ATP levels. p66Shc expression also caused a dramatic alteration in the cells' $\mathrm{Ca}^{2+}$-handling ability, which resulted in $\mathrm{Ca}^{2+}$ overload after $\mathrm{A23187}$ treatment. The impairment in $\mathrm{Ca}^{2+}$ homeostasis was ROS dependent and caused by defective $\mathrm{Ca}^{2+}$ extrusion due at least in part to decreased plasma membrane ATPase (PMCA) expression. Both effects of p66Shc required $\mathrm{Ca}^{2+}$-dependent serine-36 phosphorylation. The mitochondrial effects of p66Shc were potentiated by but not strictly dependent on the rise in $\left[\mathrm{Ca}^{2+}\right]_{c}$. Thus, $\mathrm{Ca}^{2+}$-dependent p66Shc phosphorylation causes both mitochondrial dysfunction and impaired $\mathrm{Ca}^{2+}$ homeostasis, which synergize in promoting $\mathrm{T}$ cell apoptosis.

Cell Death and Differentiation (2007) 14, 338-347. doi:10.1038/sj.cdd.4401997; published online 23 June 2006

p66Shc is a splice variant of p52Shc/p46Shc, a cytosolic adaptor controlling mitogenic signaling from tyrosine kinases to Ras. ${ }^{1}$ Although the domain organization is identical in the three isoforms, p66Shc not only fails to activate Ras, but competitively inhibits signaling by the other isoforms. ${ }^{2-4}$ Furthermore, p66Shc is implicated in signaling pathways linking oxidative stress to apoptosis. ${ }^{5}$ This property maps to a unique $\mathrm{N}$-terminal domain containing a critical serine residue at position 36, which is phosphorylated in response to stress. ${ }^{4,6-8}$ Inactivation of the gene encoding p66Shc in the mouse results in prolonged life span, ${ }^{6}$ which has been ascribed to a decreased production of reactive oxygen species (ROS) ${ }^{9,10}$ Furthermore, p66Shc gene ablation results in protection from oxidative stress-related pathologies in mouse disease models, including high-fat-diet-induced atherogenesis ${ }^{11}$ and muscular and endothelial cell apoptosis in acute ischemia. ${ }^{12}$

p66Shc-mediated apoptosis is strictly related to oxidative stress and induction of the intrinsic, mitochondrial pathway. ${ }^{6,10}$ A fraction of p66Shc localizes to mitochondria as a complex with Hsp70, wherefrom it is released upon UV irradiation. ${ }^{13}$ Mitochondrial p66Shc increases ROS production and favors opening of the permeability transition pore (PTP), ${ }^{13}$ a high-conductance inner membrane channel involved in the apoptotic response to a number of stimuli. ${ }^{14}$ The mechanism whereby p66Shc mediates mitochondrial ROS production has been recently clarified with the demon- stration that p66Shc is a redox enzyme able to oxidize cytochrome $c$ and produce $\mathrm{H}_{2} \mathrm{O}_{2}$, causing PTP opening and apoptosis. $^{15}$

Unlike p52Shc/p46Shc, which are ubiquitously expressed, p66Shc is not expressed in neurons and hemopoietic cells as a result of promoter methylation. ${ }^{16}$ We have, however, shown that $\mathrm{T}$ cells express p66Shc in response to a variety of apoptogenic stimuli, resulting in sensitization to apoptosis. Conversely, inactivation of the p66Shc gene protects T cells from dexamethasone-induced apoptosis. ${ }^{4}$ Here, we have investigated the mechanisms whereby p66Shc primes T cells to death by the $\mathrm{Ca}^{2+}$ ionophore $\mathrm{A} 23187$, a potent inducer of apoptosis that causes PTP opening in other systems. ${ }^{17} \mathrm{We}$ show that p66Shc promotes $T$ cell apoptosis both by triggering cytochrome $c$ release and mitochondrial membrane depolarization, and by impairing $\mathrm{Ca}^{2+}$ homeostasis due to downregulation of plasma membrane ATPases and defective $\mathrm{Ca}^{2+}$ extrusion. These two independent activities, which both require $\mathrm{Ca}^{2+}$-dependent p66Shc phosphorylation at $\mathrm{S} 36$, are likely to synergize in mediating p66Shc-dependent apoptosis.

\section{Results}

p66Shc sensitizes $T$ cells to apoptosis by impairing mitochondrial integrity. The apoptogenic activity of p66Shc in fibroblasts has been ascribed to its capacity to

${ }^{1}$ Department of Evolutionary Biology, University of Siena, Siena I-53100, Italy; ${ }^{2}$ Department of Biomedical Sciences and CNR Institute of Neuroscience, University of Padova, Padova I-35121, Italy and ${ }^{3}$ Department of Molecular Oncology, European Institute of Oncology, Milano I-20141, Italy

*Corresponding author: CT Baldari, Department of Evolutionary Biology, University of Siena, Via Aldo Moro 2, 53100 Siena, Italy. Tel. +39 0577 234400;

Fax + 390577 234476; E-mail: baldari@ unisi.it

${ }^{4}$ The first two authors contributed equally to this work.

Keywords: Shc proteins; apoptosis; mitochondria; calcium homeostasis; plasma membrane ATPase; serine phosphorylation

Abbreviations: PTP, permeability transition pore; ROS, reactive oxygen species; CPLA2, cytosolic phospholipase A2; PMCA, plasma membrane ATPase; GFP, green fluorescent protein; NF-AT, nuclear factor of activated T cells; TMRM, tetramethylrhodamine methyl ester; AICD, activation-induced cell death

Received 03.3.06; revised 18.5.06; accepted 19.5.06; Edited by G Melino; published online 23.6.06 
promote production of ROS which, by inducing PTP opening, cause mitochondrial damage, cytochrome $c$ release and activation of the caspase cascade. ${ }^{10,13,15}$ To understand the mechanisms underlying $T$ cell priming to apoptosis by p66Shc, we used Jurkat $\mathrm{T}$ cell transfectants stably expressing either wild-type p66Shc or a substitution mutant where S36 was mutated to alanine (p66SA) (Figure 1a). Apoptosis was induced using the $\mathrm{Ca}^{2+}$ ionophore $\mathrm{A} 23187$. In agreement with previous results, ${ }^{4}$ p66Shc potentiated A23187-induced cell death, as measured both by annexin-V staining (Figure 1b) and by Trypan Blue exclusion (Figure 1c). Interestingly, untreated p66Shc-expressing cells displayed unique morphological features compared to control cells, including accumulation of lipid vesicles, abundant cytoplasmic protrusions at the cell surface and - of particular relevance to the apoptogenic activity of p66Shc - significant amounts of dense heterochromatin (Figure 1d).

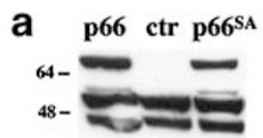

$$
\text { WB- }
$$
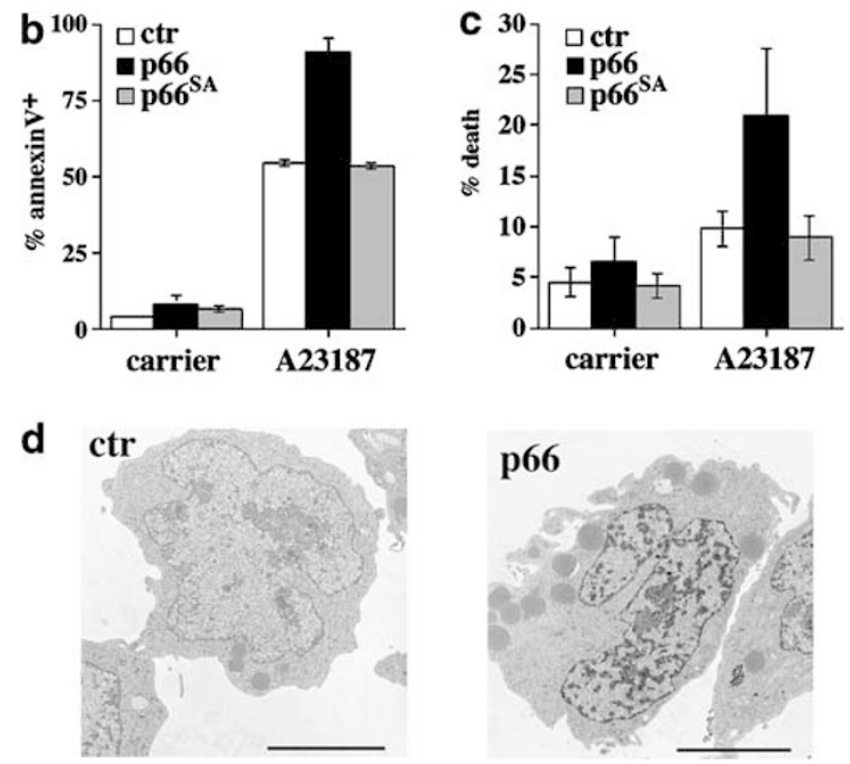

Figure 1 p66Shc expression enhances Jurkat T-cell susceptibility to A23187induced apoptosis. (a) Immunoblot analysis using anti-Shc antibodies of postnuclear supernatants of Jurkat cells stably transfected with empty vector (ctr) or with expression constructs encoding either wild-type p66Shc (p66) or a mutant carrying a serine to alanine substitution at position 36 (p66SA). The migration of molecular mass markers is indicated. (b) Quantitation by flow cytometry of annexin $V$ staining on control or p66Shc/p66SA-expressing cells after treatment for 20 min with either carrier or $500 \mathrm{ng} / \mathrm{ml} \mathrm{A23187}$. The graph shows the $\%$ of annexin- $\mathrm{V}^{+}$cells $(n=3)$. (c) Quantitation of cell death by Trypan blue exclusion in the same T-cell lines after treatement for $6 \mathrm{~h}$ in serum-free medium with either carrier or $500 \mathrm{ng} / \mathrm{ml}$ A23187 ( $n>3)$. (d) Electron micrographs of thin sections of untreated control and p66Shc-expressing cells. The size bar indicates $5 \mu \mathrm{m}$. Representative cells are shown
To assess whether p66Shc triggers the mitochondrial apoptosis pathway in $\mathrm{T}$ cells, mitochondrial integrity was monitored using the fluorescent probe tetramethylrhodamine methyl ester (TMRM), which accumulates in energized mitochondria wherefrom it is released upon membrane depolarization. Flow cytometric analysis of TMRM fluorescence revealed that $\mathrm{A} 23187$ treatment caused rapid and complete mitochondrial depolarization in p66Shc-expressing, but not in control cells (Figure 2a). In agreement with a mitochondrial involvement in the amplification by p66Shc of A23187-induced apoptosis, release of cytochrome $c$ was strongly enhanced in p66Shc-expressing cells (Figure 2b). Furthermore, measurement of cellular ATP showed not only the expected reduction in both cell lines following A23187 treatment but also significantly lower ATP levels in untreated p66Shc-expressing cells compared to controls (Figure 2c). Of note, enhancement of mitochondrial depolarization and cytochrome $c$ release by p66Shc, which correlated with enhanced apoptosis, was also found in cells triggered to undergo activation-induced death (AICD) by prolonged TCR/ CD3 ligation (Figure 3). Hence, p66Shc expression results in mitochondrial dysfunction.

Electron microscopic analysis revealed that the mitochondrial morphology of untreated control and p66Shc-expressing cells was similar, with an electron-transparent matrix and thin, tubular cristae. A23187 treatment resulted in increased electron density of the mitochondrial matrix in both cell types, a change that in p66Shc-expressing cells was accompanied by the presence of fewer cristae of larger dimensions and by a marked increase of the intercristal space, indicative of extensive mitochondrial remodeling. A23187 treatment also led to defects of the inner and outer mitochondrial membranes, resulting in the absence of a clear boundary between matrix and cytosol, which was particularly striking in p66Shcexpressing cells (Figure $2 \mathrm{~d}$ ).

p66Shc induces apoptosis in fibroblasts by triggering PTP opening. ${ }^{13}$ Opening of the PTP in response to a number of stimuli, including $\mathrm{Ca}^{2+}$, arachidonic acid and ROS, results in osmotic swelling of the mitochondria followed by outer membrane rupture, cytochrome $c$ release, ATP depletion and cell death. ${ }^{18}$ To investigate the potential role of PTP opening in mitochondrial membrane permeabilization and cytochrome $c$ release in T cells, p66Shc-expressing cells were treated with cyclosporin A (CsA), which desensitizes the PTP by interacting with cyclophilin D. ${ }^{18}$ Neither the kinetics nor the extent of mitochondrial depolarization were modified by CsA (Figure 2e). Similar results were obtained after treatment with sanglifehrin A, another PTP inhibitor that targets cyclophilin D (results not shown), suggesting that PTP opening may not play a major role in mitochondrial depolarization associated with p66Shc expression in A23187-treated cells. This possibility was further explored using a different approach to modulate PTP function. We have previously shown that in hepatoma cells A23187 triggers $\mathrm{Ca}^{2+}$-dependent PTP opening through activation of cytosolic phospholipase A2 $\left(\mathrm{CPLA}_{2}\right)$ and production of arachidonic acid. ${ }^{17} \mathrm{We}$ therefore tested whether A23187-induced mitochondrial depolarization in p66Shc-expressing cells could be inhibited by the $\mathrm{CPLA}_{2}$ inhibitor aristolochic acid or potentiated by inhibition of 5-lipoxygenase by MK886 and cyclooxygenases 
a

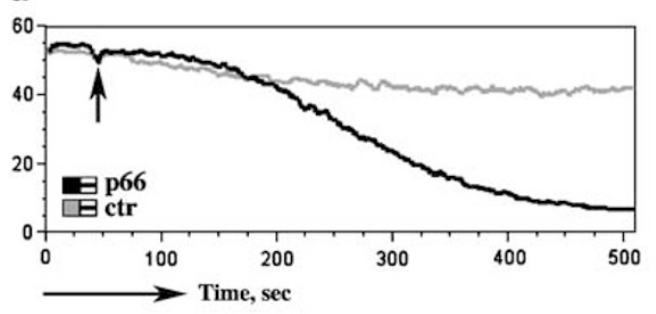

b

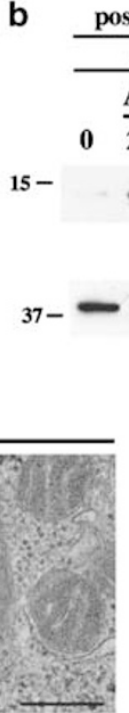

d
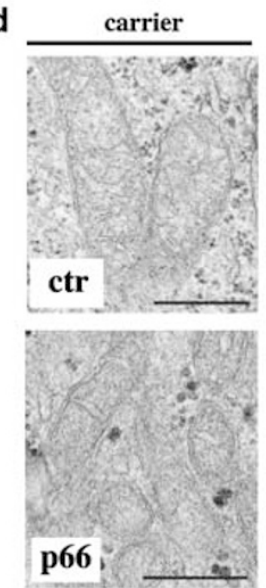

A23187
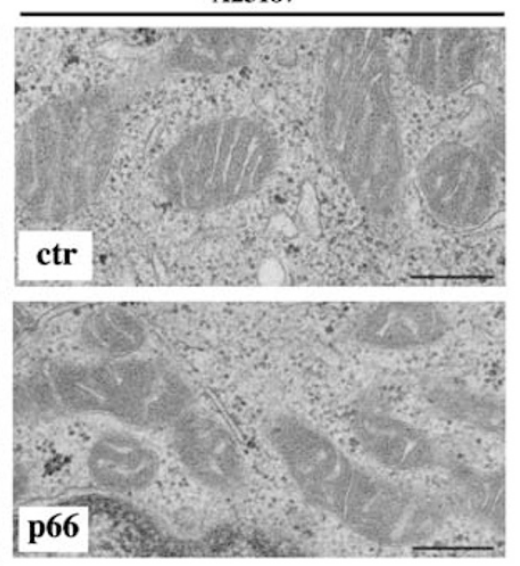

post-mitochondrial sup

$\frac{\text { ctr }}{\mathbf{A 2 3 1 8 7}} \frac{\mathbf{p 6 6}}{\mathbf{A 2 3 1 8 7}} \frac{\begin{array}{c}\text { total cell } \\ \text { lysates }\end{array}}{\text { y }}$

$\begin{array}{llllll}2 \mathrm{~h} \quad 6 \mathrm{~h} & 0 & \frac{\mathrm{A} 23187}{2 \mathrm{~h} \quad 6 \mathrm{~h}} & \text { ctr p66 }\end{array}$

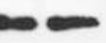

WB anti-cytC

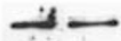

WB anti-Erk

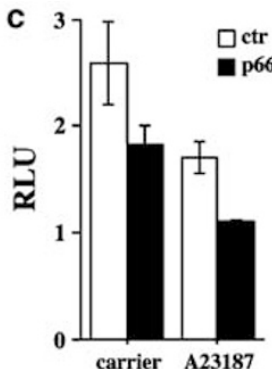

e

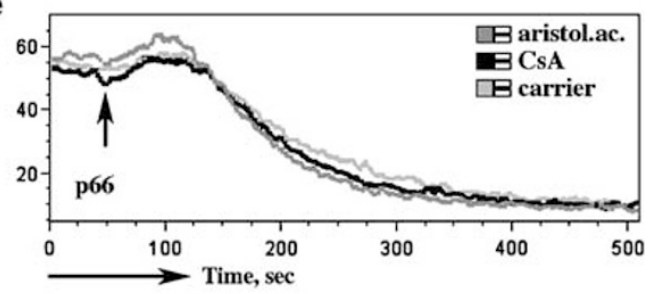

f

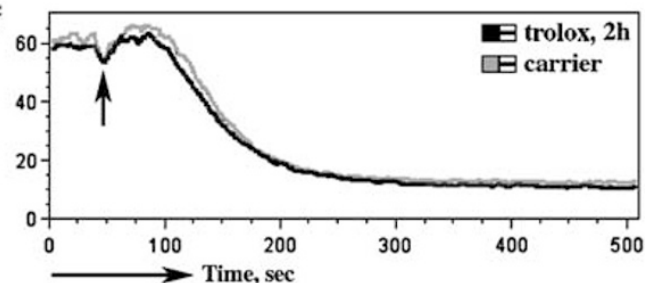

Figure 2 p66Shc expression results in mitochondrial dysfunction. (a) Flow cytometric analysis of mitochondrial membrane potential in TMRM-loaded control (gray line) and p66Shc-expressing (black line) Jurkat cells. TMRM was loaded to a comparable extent in both cell lines, as evaluated by fluorimetric analysis of cells lysed with digitonin (not shown). The arrow indicates the time of addition of A23187 (top) or anti-CD3 mAb (bottom). Representative experiments are shown ( $n>3$ ). (b) Immunoblot analysis using cytochrome $c$ antibodies of post-mitochondrial supernatants of lysates from control and p66Shc-expressing Jurkat cells either untreated or stimulated for the indicated times with $500 \mathrm{ng} / \mathrm{ml}$ A23187. As control of anti-cytochrome $c$ expression in the two cell transfectants, a blot on total cell lysates is shown on the right. Control blots of the stripped filters are shown below. The migration of molecular mass markers is indicated $(n>3)$. (c) Relative levels of ATP in control and p66Shc-expressing cells treated with either carrier or $500 \mathrm{ng} / \mathrm{ml} \mathrm{A} 23187$ for $20 \mathrm{~min}$. RLU, relative light units $(n=3)$. (d) Electron micrographs of thin sections of control and p66Shc-expressing cells, treated for $20 \mathrm{~min}$ with either carrier or $500 \mathrm{ng} / \mathrm{ml} \mathrm{A23187}$. The size bar represents $0.3 \mu \mathrm{m}$. Representative images are shown. (e, f) Flow cytometric analysis of mitochondrial membrane potential in TMRM-loaded p66Shc-expressing cells treated with $500 \mathrm{ng} / \mathrm{ml} \mathrm{A23187} \mathrm{after} \mathrm{a} 30$ min pretreatment with carrier (light gray line), $50 \mu \mathrm{M}$ aristolochic acid (dark gray line) or $1 \mu \mathrm{g} / \mathrm{ml} \mathrm{CsA} \mathrm{(black} \mathrm{line)} \mathrm{(e),} \mathrm{or} \mathrm{a} 2 \mathrm{~h}$ pretreatment with carrier (light gray line) or $2 \mathrm{mM}$ Trolox (black line) (f). The arrow indicates the time of addition of A23187 ( $n \geqslant 3$ )

by indomethacin, a treatment that results in arachidonic acid accumulation. ${ }^{17}$ These treatments did not affect the mitochondrial membrane potential response to A23187 (Figure 2e and data not shown).

Of note, neither treatment of p66Shc-expressing cells with the antioxidant Trolox, a lipophilic vitamin $\mathrm{E}$ analog, or treatment of control cells with $\mathrm{H}_{2} \mathrm{O}_{2}$, modified to any significant extent the respective kinetics of mitochondrial membrane depolarization in response to $\mathrm{A} 23187$ (Figure $2 \mathrm{f}$ and data not shown). Hence, while p66Shc triggers the mitochondrial pathway of apoptosis in T cells, the mechanism responsible for mitochondrial recruitment does not appear to involve ROS-dependent PTP opening, at variance with fibroblasts. ${ }^{13}$ Trolox treatment abrogated however the enhanced apoptotic response to A23187 of p66Shc-expressing cells (Figure 4), suggesting a role for p66Shc-dependent ROS production in additional apoptotic pathways independent of mitochondria. Support to this hypothesis comes from the functional analysis of the p66Shc S36 mutant (p66SA). Phosphorylation of this residue has been shown to be essential for the apoptogenic activity of p66Shc $\left({ }^{4,6,7}\right.$ and Figure 1$)$, but not for the oxidizing activity of the mitochondrial pool of the protein. ${ }^{15}$ As opposed to its wild-type counterpart, p66SA expression did not induce mitochondrial dysfunction in A23187-treated cells, as assessed by lack of mitochondrial depolarization (Figure 5a) and cytochrome $c$ release (Figure 5b). As S36-phosphorylated p66Shc is only found in the cytosol, ${ }^{15}$ the data collectively indicate that p66Shc triggers not only the mitochondrial pathway of apoptosis but also an additional, extramitochondrial pathway.

p66Shc impairs $\mathrm{Ca}^{2+}$ homeostasis in $\mathrm{T}$ cells. By promoting activation of many proapoptotic molecules and expression of proapoptotic genes, $\mathrm{Ca}^{2+}$ acts a key player both in the intrinsic and extrinsic apoptosis pathways. ${ }^{19}$ Among the latter of particular relevance to $T$ cells is the $\mathrm{Ca}^{2+}$-dependent pathway controlling AICD. ${ }^{20}$ To assess whether the proapoptotic activity of p66Shc may be related to alterations in $\left[\mathrm{Ca}^{2+}\right]_{\mathrm{c}}$, the kinetics of $\left[\mathrm{Ca}^{2+}\right]_{\mathrm{c}}$ mobilization in response to $A 23187$ was determined by flow cytometric analysis of Fluo-4-loaded cells. Control cells responded with an initial increase in $\left[\mathrm{Ca}^{2+}\right]_{\mathrm{c}}$, which consistently dropped to lower levels within 2 min. Remarkably, p66Shc-expressing cells underwent a larger early $\left[\mathrm{Ca}^{2+}\right]_{c}$ rise that was followed 

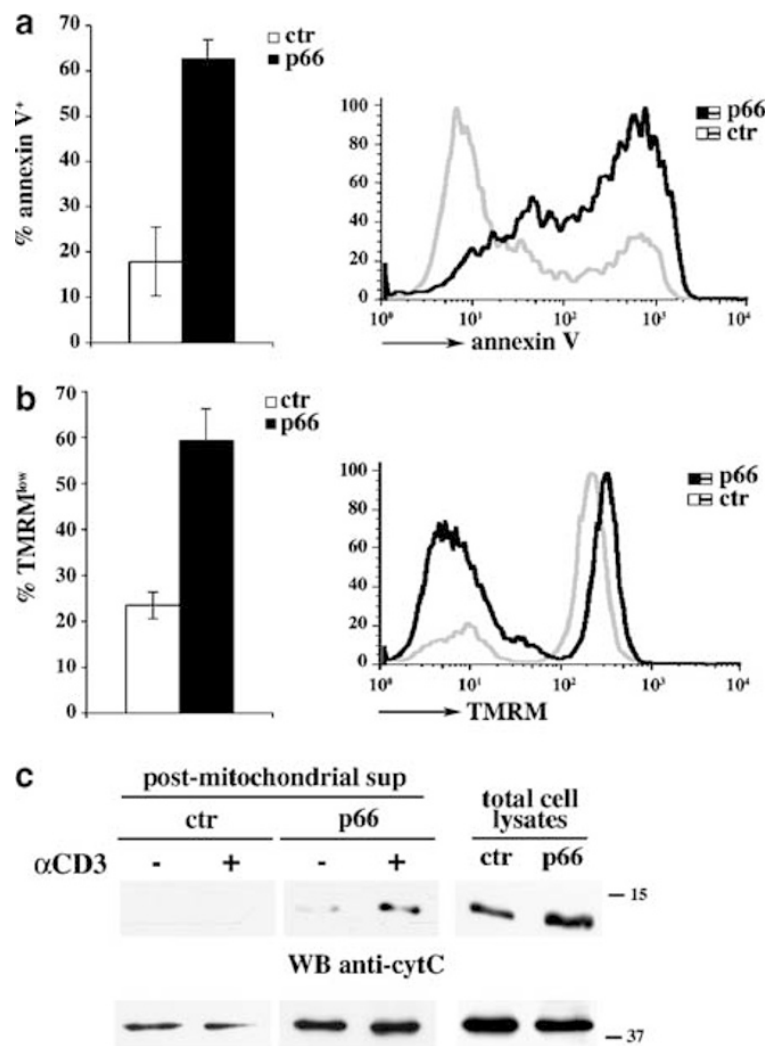

WB anti-Erk

Figure 3 p66Shc expression enhances mitochondrial dysfunction in AICD. (a) Quantitation by flow cytometry of annexin-V staining on control or p66Shcexpressing cells after treatment for $48 \mathrm{~h}$ with saturating amounts of plate-bound anti$\mathrm{CD} 3 \mathrm{mAb}(n=3)$. Representative histograms are shown on the right (control cells, gray line; p66Shc-expressing cells, black line). (b) Flow cytometric analysis of mitochondrial membrane potential in TMRM-loaded control or p66Shc-expressing cells treated as above and restimulated for $6 \mathrm{~h}$ with anti-CD3 mAb. The graph shows the percentage of depolarized cells (TMRM $\left.{ }^{\mathrm{low}}\right)(n=3)$. Representative histograms are shown on the right (control cells, gray line; p66Shc-expressing cells, black line). (c) Immunoblot analysis using cytochrome $c$ antibodies of post-mitochondrial supernatants of lysates from control and p66Shc-expressing Jurkat cells treated as above. As control of cytochrome $c$ expression, a blot on total cell lysates is also shown. Control blots of the stripped filters are shown below

by $\mathrm{Ca}^{2+}$ deregulation, as shown by a dramatic and sustained further increase in $\left[\mathrm{Ca}^{2+}\right]_{c}$ (Figure 6a). Pretreatment with thapsigargin, a drug that depletes intracellular $\mathrm{Ca}^{2+}$ stores, normalized the early $\left[\mathrm{Ca}^{2+}\right]_{c}$ rise and partially reduced the late phase of $\left[\mathrm{Ca}^{2+}\right]_{c}$ increase. On the other hand, pretreatment with EGTA, a cell-impermeant $\mathrm{Ca}^{2+}$ chelator, normalized both the early and late $\left[\mathrm{Ca}^{2+}\right]_{c}$ responses to A23187 (Figure 6b). These findings indicate that both external $\mathrm{Ca}^{2+}$ and intracellular stores contribute to the overwhelming $\left[\mathrm{Ca}^{2+}\right]_{c}$ responses of p66Shc-expressing cells. $\mathrm{Ca}^{2+}$ depletion by combined treatment with EGTA and thapsigargin, which restored normal $\mathrm{Ca}^{2+}$ responses (Figure 6b), fully protected p66Shc-expressing cells from apoptosis (Figure 4), underlining the causal role of the observed $\mathrm{Ca}^{2+}$ overload in the enhanced A23187-induced apoptosis of these cells.

Of note, even after treatment with EGTA, alone or in combination with thapsigargin, p66Shc-expressing cells

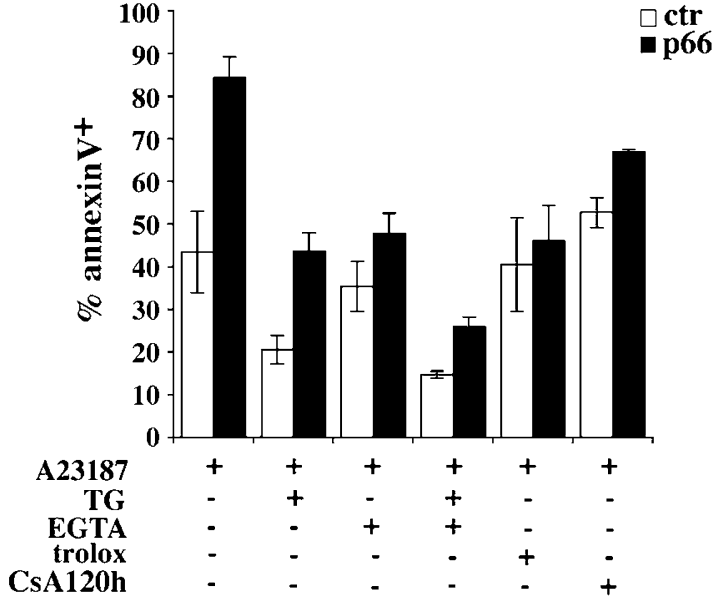

Figure 4 p66Shc-dependent apoptosis requires $\mathrm{Ca}^{2+}$ and ROS. Quantitation by flow cytometry of annexin- $V$ staining on control or p66Shc-expressing cells after treatment for $20 \mathrm{~min}$ with either carrier or $500 \mathrm{ng} / \mathrm{ml} \mathrm{A23187}$. Cells were pretreated for 40 min with EGTA $(5 \mathrm{mM})$ or thapsigargin $(2 \mu \mathrm{M})$, alone or in combination, or pretreated for $2 \mathrm{~h}$ with $2 \mathrm{mM}$ Trolox, or treated for $120 \mathrm{~h}$ with $1 \mu \mathrm{g} / \mathrm{ml} \mathrm{CsA}$. The graph shows the $\%$ of annexin- $V^{+}$cells $(n \geqslant 3)$

displayed a larger early $\left[\mathrm{Ca}^{2+}\right]_{c}$ increase in response to A23187 (Figure 6c), suggesting that p66Shc increases the $\mathrm{Ca}^{2+}$ contents of intracellular stores. In agreement with this possibility, thapsigargin treatment in the absence of A23187 resulted in increased $\left[\mathrm{Ca}^{2+}\right]_{c}$ in p66Shc-expressing cells compared to controls (Figure 6d). Furthermore, p66Shc caused a larger increase of $\left[\mathrm{Ca}^{2+}\right]_{\mathrm{c}}$ after TCR/CD3 engagement. It should be underlined that the TCR/CD3-dependent increase in $\left[\mathrm{Ca}^{2+}\right]_{c}$ returned to basal levels with the same time course as that of control cells (Figure 6d), suggesting that p66Shc-expressing cells can handle the relatively modest increase of $\left[\mathrm{Ca}^{2+}\right]_{\mathrm{c}}$ induced by physiological stimulation but not the massive $\mathrm{Ca}^{2+}$ overload induced by $\mathrm{A} 23187$.

To understand whether the increased ROS production in p66Shc-expressing cells is implicated in the observed A23187-induced $\mathrm{Ca}^{2+}$ deregulation, we measured the kinetics of $\left[\mathrm{Ca}^{2+}\right]_{c}$ mobilization in response to A23187 after cell treatment with the antioxidant Trolox. This treatment resulted in a significant amelioration of the $\mathrm{Ca}^{2+}$-handling ability of p66Shc-expressing cells (Figure 6e). Conversely, exposure of control cells to $\mathrm{H}_{2} \mathrm{O}_{2}$ resulted in $\mathrm{Ca}^{2+}$ deregulation (Figure 6f). Taken together with inability of Trolox to restore mitochondrial integrity in p66Shc-expressing cells (Figure 2f), notwithstanding its protective effect on A23187induced apoptosis (Figure 4), these data suggest that the ROS-dependent pathway of apoptosis triggered by p66Shc involves $\mathrm{Ca}^{2+}$ deregulation. In agreement with the requirement for S36 phosphorylation in p66Shc-dependent apoptosis (Figure 1) and the role of impaired $\mathrm{Ca}^{2+}$ homeostasis in this process (Figure 4), cells expressing the p66SA mutant displayed a normal $\left[\mathrm{Ca}^{2+}\right]_{\mathrm{C}}$ response (Figure $5 \mathrm{c}$ ).

p66Shc downregulates plasma membrane $\mathrm{Ca}^{2+}$ ATPases. Plasma membrane $\mathrm{Ca}^{2+}$ ATPases (PMCA) play a key role in $\mathrm{Ca}^{2+}$ homeostasis. In lymphocytes, PMCAs represent the principal means to extrude $\mathrm{Ca}^{2+}$ that has 
a
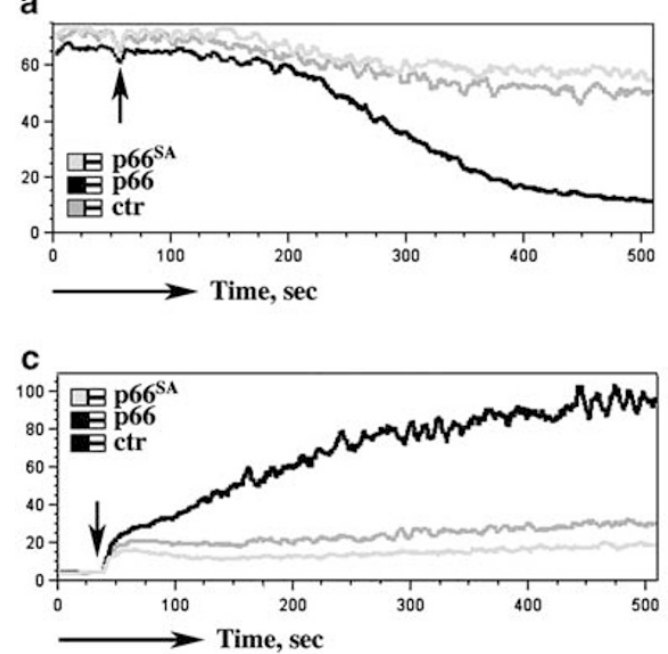

b

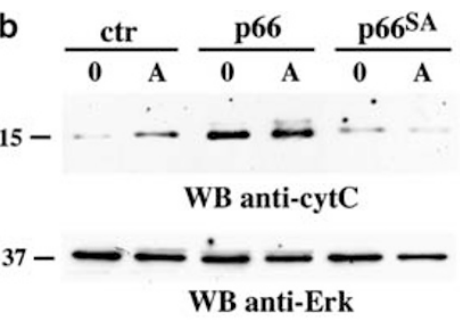

d

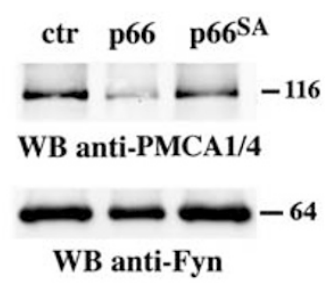

Figure 5 The effects of p66Shc on mitochondrial function and $\left[\mathrm{Ca}^{2+}\right]_{c}$ deregulation require serine 36 phosphorylation. (a) Flow cytometric analysis of mitochondrial membrane depolarization in TMRM-loaded control or p66Shc/p66SA-expressing Jurkat cells in response to $500 \mathrm{ng} / \mathrm{ml} \mathrm{A23187.} \mathrm{The} \mathrm{arrow} \mathrm{indicates} \mathrm{the} \mathrm{time} \mathrm{of} \mathrm{addition} \mathrm{of}$ A23187. Representative experiments are shown $(n>3)$. (b) Immunoblot analysis using anti-cytochrome $c$ antibodies of post-mitochondrial supernatants of lysates from control or p66Shc/p66SA-expressing Jurkat cells either untreated or stimulated for $30 \mathrm{~min}$ with $500 \mathrm{ng} / \mathrm{ml} \mathrm{A23187}$. A control blot of the stripped filter is shown below $(n=3)$. The migration of molecular mass markers is indicated. (c) Flow cytometric analysis of $\left[\mathrm{Ca}^{2+}\right]_{c}$ in Fluo-4-loaded control (dark gray line) or p66Shc (black line)/p66SA (light gray line)-expressing Jurkat cells in response to $500 \mathrm{ng} / \mathrm{ml} \mathrm{A23187.} \mathrm{The} \mathrm{arrow} \mathrm{indicates} \mathrm{the} \mathrm{time} \mathrm{of} \mathrm{addition} \mathrm{of} \mathrm{A23187.} \mathrm{Representative} \mathrm{experiments} \mathrm{are} \mathrm{shown} \mathrm{(} n>3$ ). (d) Immunoblot analysis of lipid rafts purified from control or p66Shc/p66SA-expressing cells with anti-PMCA1/4 antibodies. After stripping, the filter was reprobed with anti-Fyn antibodies as loading control

entered through CRAC channels ${ }^{21}$ and have been shown to underlie attenuation of $\mathrm{Ca}^{2+}$ signaling by the inhibitory coreceptor CD22 in B cells. ${ }^{22}$ We therefore investigated the expression levels of PMCA1/4, which are the major $\mathrm{T}$ cell species. Immunoblot analysis revealed a significant reduction in PMCA1/4 expression in lysates from p66Shcexpressing cells compared to controls (Figure 7a). PMCA1/4 was also analyzed in lipid rafts where these proteins are known to preferentially segregate. ${ }^{23}$ Lower PMCA1/4 levels were detected in rafts from p66Shc-expressing cells (Figure 7a). RT-PCR analysis with primers specific for PMCA1b, $4 a$ and $4 b$ revealed a selective reduction in the levels of PMCA4a-specific mRNA (Figure 7b).

Expression of the PMCA4 Cll splice variant has been reported to be downregulated at the transcriptional level by the $\mathrm{Ca}^{2+} / \mathrm{CaM}$-dependent phosphatase calcineurin. ${ }^{24}$ As nuclear translocation of the transcription factor nuclear factor of activated T cells (NF-AT) is exquisitely calcineurindependent, ${ }^{25}$ we used an NFAT- green fluorescent protein (GFP) fusion protein as a reporter of calcineurin activity. A plasmid encoding NFAT-GFP was transiently transfected into the Jurkat lines, and the number of cells displaying nuclear fluorescence was scored. A larger proportion of p66Shcexpressing cells displayed nuclear localization of NFAT-GFP compared to controls, both under basal conditions and after addition of A23187 (Figure 7c), indicating higher levels of calcineurin activity. To assess whether calcineurin activity was involved in downregulation of PMCA4a gene expression, p66Shc-expressing cells were subjected to long-term (120 h) treatment with CsA, which inhibits calcineurin after binding to cyclophilin A. This treatment led to recovery of PMCA expression to the levels observed in control cells (Figure 7d).
Under these conditions, no $\mathrm{Ca}^{2+}$ deregulation was observed after A23187 treatment (Figure 7e), and apoptosis was reduced, although protection was partially offset by toxicity of the immunosuppressant, which can be appreciated by increased apoptosis in control cells (Figure 4).

Cells expressing the p66SA mutant, which did not display any impairment in $\mathrm{Ca}^{2+}$ homeostasis, expressed PMCA1/4 to the same levels as control cells (Figure $5 \mathrm{~d}$ ). Furthermore, the relative levels of PMCA4a-specific mRNA in p66SA-expressing cells were comparable to those in controls $(96.3 \% \pm 6.0$ of the mRNA levels found in control cells; $n=3$ ), as was the proportion of cells harboring basal nuclear NF-AT localization (data not shown). Hence, downregulation of PMCA1/4, resulting at least in part from attenuation of PMCA4a gene transcription, is tightly correlated with the decreased ability of p66Shc-expressing cells to handle the massive $\mathrm{Ca}^{2+}$ overload induced by A23187. The important role of PMCAs in the defective p66Shc-dependent $\mathrm{Ca}^{2+}$ homeostasis is underlined by the finding that pretreatment of control cells with sodium vanadate, a PMCA inhibitor, resulted in an A23187induced $\mathrm{Ca}^{2+}$ mobilization profile similar to the one observed in p66Shc-expressing cells (Figure 7f).

The effects of p66Shc on mitochondrial integrity and $\mathrm{Ca}^{2+}$ homeostasis are independent but both require $\mathrm{Ca}^{2+}$, which is essential for S36 phosphorylation. In addition to promoting PTP opening, $\mathrm{Ca}^{2+}$ has other mitochondrial targets implicated in apoptosis, including proapoptotic members of the $\mathrm{Bcl}-2$ protein family such as Bad, which is sequestered in the cytosol through its association with 14-3-3, and cardiolipin, an anionic phospholipid that mediates cytochrome $c$ association with 
a

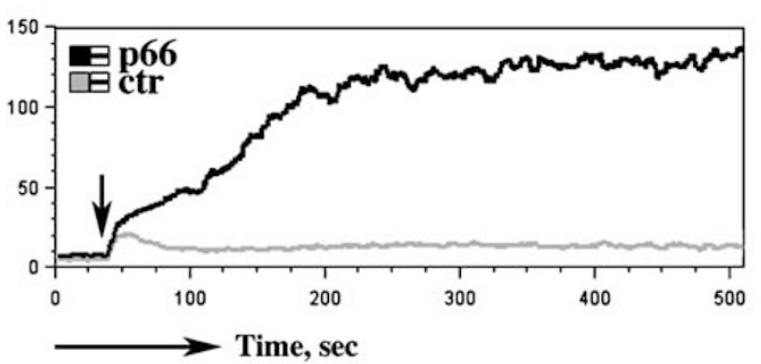

C
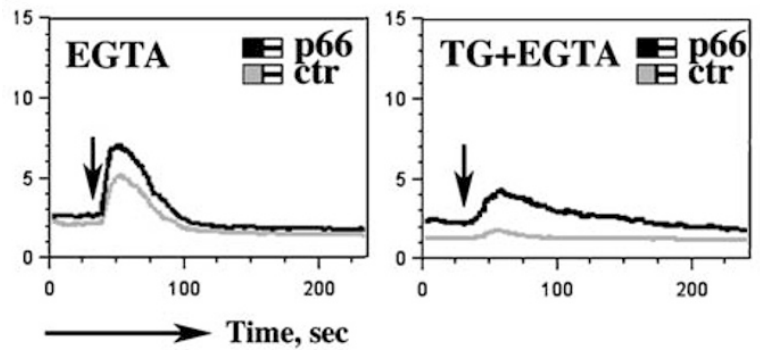

e

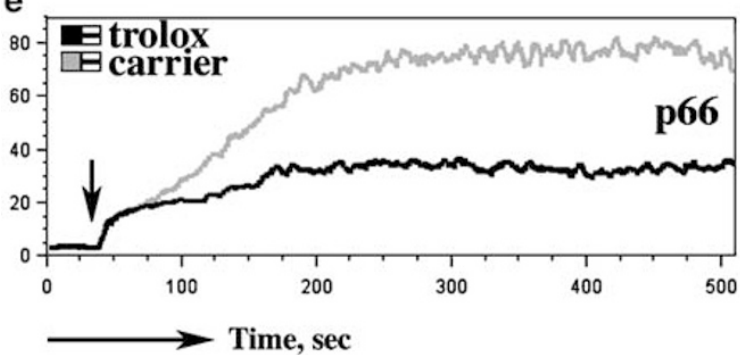

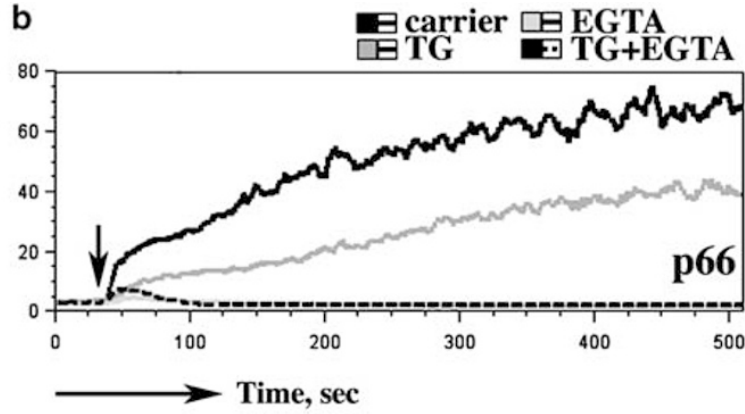

d
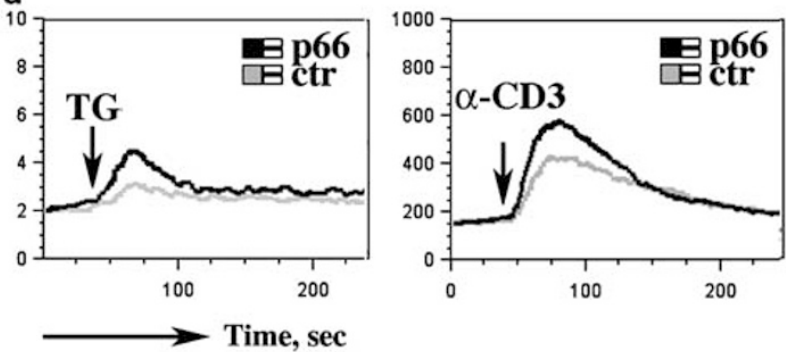

f

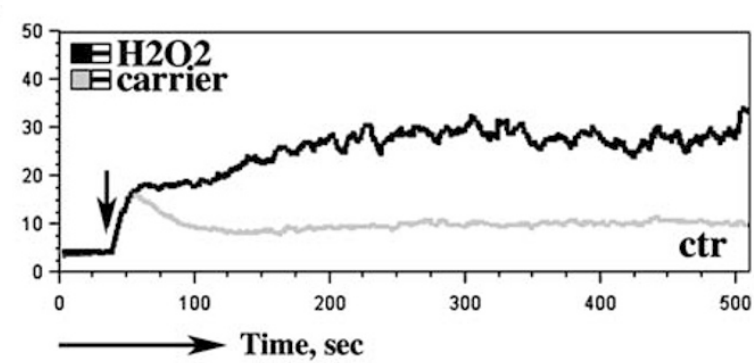

Figure 6 Expression of p66Shc results in $\left[\mathrm{Ca}^{2+}\right]_{c}$ deregulation. (a) Flow cytometric analysis of $\left[\mathrm{Ca}^{2+}\right]_{c}$ in Fluo-4-loaded control (gray line) or p66Shc-expressing (black line) Jurkat cells in response to $500 \mathrm{ng} / \mathrm{ml}$ A23187. Fluo-4 was loaded to a comparable extent in both cell lines, as evaluated by fluorimetric analysis of cells lysed with digitonin (not shown). Representative experiments are shown $(n>3)$. (b) Flow cytometric analysis of $\left[\mathrm{Ca}^{2+}\right]_{c}$ in Fluo-4-loaded p66Shc-expressing Jurkat cells treated with $500 \mathrm{ng} / \mathrm{ml}$ A23187 in the presence of carrier (black line), thapsigargin ( $2 \mu \mathrm{M})$ (TG, dark gray line) or EGTA (5mM), alone (light gray solid line) or in combination with thapsigargin (black dashed line). The initial phase of the kinetics of a representative experiment is shown on an expanded scale in panel (c). The arrow indicates the time of addition of A23187. (d) Flow cytometric analysis of $\left[\mathrm{Ca}^{2+}\right]_{\mathrm{c}}$ in Fluo-4-loaded control (gray line) or p66Shc-expressing (black line) Jurkat cells treated with either thapsigargin (2 $\left.\mu \mathrm{M}\right)(\mathrm{TG})$ or anti$\mathrm{CD} 3 \mathrm{mAb}$. The arrow indicates the time of addition of the stimulus. (e, f) Flow cytometric analysis of $\left[\mathrm{Ca}^{2+}\right]_{\mathrm{c}}$ in Fluo-4-loaded p66Shc-expressing cells treated for $1 \mathrm{~h}$ with $2 \mathrm{mM}$ Trolox (e) or control cells treated for 40 min with $440 \mu \mathrm{M} \mathrm{H}_{2} \mathrm{O}_{2}$ (f). Gray lines, carrier; black lines, Trolox (e) or $\mathrm{H}_{2} \mathrm{O}_{2}$ (f). The arrow indicates the time of addition of A23187. Representative experiments are shown $(n \geqslant 3)$

the inner mitochondrial membrane. ${ }^{19}$ To understand whether the $\mathrm{Ca}^{2+}$ overload in p66Shc-expressing cells treated with A23187 was responsible for mitochondrial dysfunction, we asked whether long-term treatment of p66Shc-expressing cells with CsA, which results in normalization of the $\mathrm{Ca}^{2+}$ response (Figure 7e), would prevent mitochondrial depolarization. Surprisingly, CsA treatment did not modify either the dissipation of the mitochondrial membrane potential (Figure $7 \mathrm{~g}$ ) or the enhancement in cytochrome $c$ release triggered by $\mathrm{A} 23187$ (Figure $7 \mathrm{~h}$ ). Taken together with the failure of Trolox to restore mitochondrial function despite the normalization of the $\mathrm{Ca}^{2+}$ response (Figures $2 \mathrm{f}$ and $6 \mathrm{e}$ ), the results indicate that, while $\mathrm{Ca}^{2+}$ overload is likely to amplify the mitochondrial dysfunction in p66Shc-expressing cells, these two activities are independent.

Surprisingly, depletion of $\mathrm{Ca}^{2+}$ by cell treatment with EGTA and thapsigargin, which restored normal $\mathrm{Ca}^{2+}$ responses
(Figure 6b), also completely abrogated the mitochondrial depolarization triggered by A23187 (Figure 8a). These findings suggest that, while $\mathrm{Ca}^{2+}$ overload and mitochondrial dysfunction are independent effects of p66Shc, $\mathrm{Ca}^{2+}$ is required for both. We had previously observed that in Jurkat $T$ cells p66Shc displays a basal level of S36 phosphorylation that can be enhanced by a variety of receptor-mediated and pharmacological stimuli including A23187, all of which cause a transient rise of $\left[\mathrm{Ca}^{2+}\right]_{\mathrm{C}} .{ }^{4}$ We hypothesized that the $\left[\mathrm{Ca}^{2+}\right]_{\mathrm{C}}$ rise could be essential for p66Shc phosphorylation at S36. We therefore measured the effect of $\mathrm{A} 23187, \mathrm{H}_{2} \mathrm{O}_{2}$ and CD3 ligation on p66Shc phosphorylation at $\mathrm{S} 36$ in $\mathrm{Ca}^{2+}$-competent cells and after $\mathrm{Ca}^{2+}$ depletion by treatment with thapsigargin and EGTA. p66Shc phosphorylation was abolished by this treatment in all conditions tested (Figure $8 \mathrm{~b}$ ). While suppression of phosphorylation by A23187 was predictable, it is striking that $\mathrm{Ca}^{2+}$ depletion suppressed the 
basal level of phosphorylation and prevented its enhancement by stimuli that do not affect $\mathrm{Ca}^{2+}$ mobilization directly. These results demonstrate that $\mathrm{Ca}^{2+}$ is strictly required for p66Shc phosphorylation by physiological and pharmacological stimuli. This requirement is likely to underlie the $\mathrm{Ca}^{2+}$ dependency of both mitochondrial dysfunction and impaired $\mathrm{Ca}^{2+}$ homeostasis associated with p66Shc expression.

a
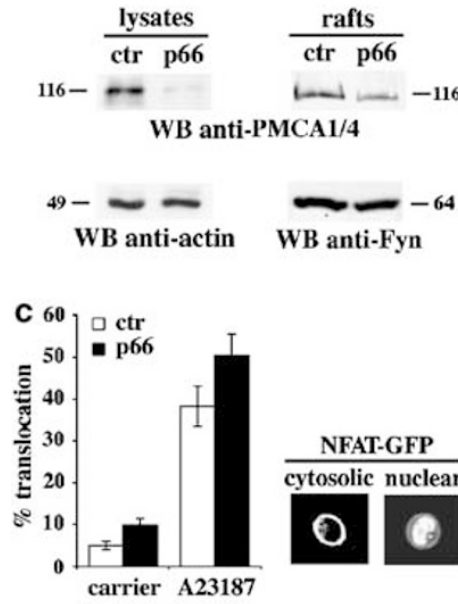

NFAT-GFP $\overline{\text { cytosolic nuclear }}$ 0 Q

e

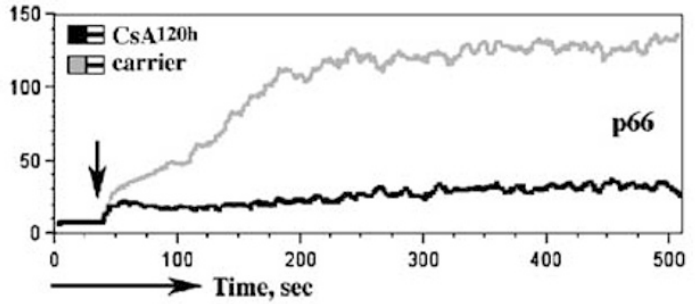

f

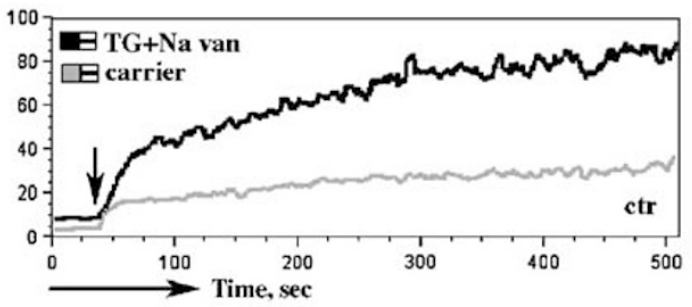

g

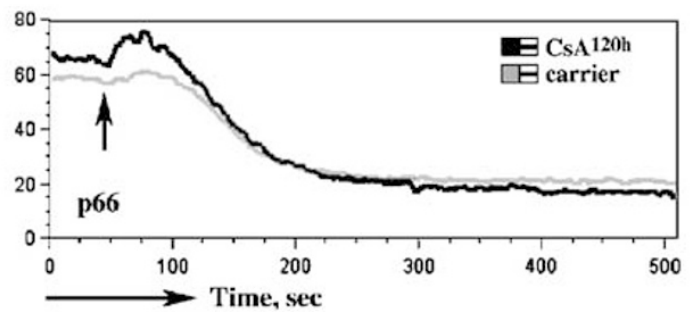

h

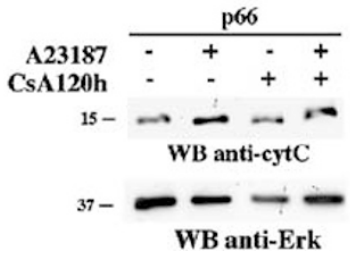

\section{Discussion}

Our data show that p66Shc sensitizes $\mathrm{T}$ cells to $\mathrm{Ca}^{2+}$ dependent apoptosis through two distinct activities. The first involves mitochondrial dysfunction, as revealed by cytochrome $c$ release, dissipation of mitochondrial transmembrane potential, impaired ATP production and morphological alterations. Although loss of mitochondrial integrity is evident only following A23187 treatment, release of cytochrome $c$, as well as decreased ATP levels, can be observed even under basal conditions, albeit to a lower extent, suggesting that the apoptotic machinery is primed and can be readily recruited in response to apoptotic insults in the presence of p66Shc. This finding is in agreement with the higher frequency of p66Shcexpressing cells with apoptotic morphology compared to control cells. We have previously reported that, by affecting gene expression, p66Shc causes an imbalance between the proapoptotic/antiapoptotic Bcl-2 family members, with a reduction in Bcl- $\mathrm{x}_{\mathrm{L}}$ and an increase in Bax expression. ${ }^{4} \mathrm{By}$ oligomerizing with Bak, Bax forms pores in the outer mitochondrial membrane, resulting in cytochrome $c$ release, ${ }^{26}$ which was also observed following enforced Bax or Bak expression. ${ }^{27}$ Cytochrome $c$ release in turn decreases the rate of electron transfer and increases production of the superoxide anion, ${ }^{28}$ events that explain the observed mitochondrial depolarization and decreased ATP synthesis. Thus, increased Bax expression may underlie the mytochondrial dysfunction in p66Shc-expressing cells. Both the increased basal $\mathrm{Ca}^{2+}$ levels and the enhanced ROS production in these

Figure 7 Downregulation of PMCA4a by p66Shc. (a) Immunoblot analysis using anti-PMCA1/4 antibodies of postnuclear supernatants (left) or purified lipid rafts (right) of untreated control or p66Shc-expressing Jurkat cells. After stripping, the filters where reprobed with anti-actin (left) or anti-Fyn (a raft resident protein) antibodies as loading control. The levels of reduction of PMCA4a were reproducibly $\sim 40 \%$, as determined by laser densitometry $(n=3)$. (b) Semiquantitative RT-PCR analysis of PMCA $1 b, 4 a$ and $4 \mathrm{~b}$ mRNA levels in untreated control and p66Shcexpressing Jurkat cells. RT-PCR products were resolved by agarose gel electrophoresis, quantitated by laser densitometry and normalized to the levels of actin mRNA used as internal control. The data are expressed as \% of PMCAspecific mRNA in p66-expressing cells versus control cells (taken as 100\%) $(n>3)$. (c) Confocal microscopy of control or p66Shc-expressing Jurkat cells transiently transfected with an NFAT/GFP expression construct, treated for $30 \mathrm{~min}$ with either carrier or $500 \mathrm{ng} / \mathrm{ml}$ A23187. GFP-positive cells (50-100/sample) showing nuclear NFAT/GFP were scored $(n>3)$. The graph shows the $\%$ of cells harboring nuclear GFP. Representative images are shown on the right. (d) Immunoblot analysis of lipid rafts with anti-PMCA1/4 antibodies (bottom) of p66Shc-expressing cells treated for $120 \mathrm{~h}$ with either carrier or $1 \mu \mathrm{g} / \mathrm{ml} \mathrm{CsA}$. The levels of PMCA4a in p66Shcexpressing cells in the representative experiment shown were $~ 40 \%$ compared to the levels in control cells in the absence of CsA, while they increased to 90\% after long-term treatment with CsA, as determined by laser densitometry $(n=3)$. $(\mathbf{e}, \mathbf{f})$ Flow cytometric analysis of $\left[\mathrm{Ca}^{2+}\right]_{\mathrm{c}}$ in Fluo-4-loaded p66Shc-expressing Jurkat cells treated for $120 \mathrm{~h}$ with carrier (gray line) or $1 \mu \mathrm{g} / \mathrm{ml} \mathrm{CsA}$ (black line) (e) or for 40 min with $2 \mu \mathrm{M}$ thapsigargin (TG) and $1 \mathrm{mM}$ sodium vanadate (Na van) (black line) (f). The arrow indicates the time of addition of A23187 $(n>3)$. (g) Flow cytometric analysis of mitochondrial membrane potential in TMRM-loaded p66Shc-expressing cells treated with $500 \mathrm{ng} / \mathrm{ml} \mathrm{A23187} \mathrm{after} \mathrm{a} \mathrm{long-term}(120 \mathrm{~h})$ treatment with carrier (gray line) or $1 \mu \mathrm{g} / \mathrm{ml}$ CsA (black line). The arrow indicates the time of addition of A23187 $(n=3)$. (h) Immunoblot analysis using anti-cytochrome $c$ antibodies of post-mitochondrial supernatants of lysates from p66Shc-expressing Jurkat cells either untreated or stimulated for $30 \mathrm{~min}$ with $500 \mathrm{ng} / \mathrm{ml} \mathrm{A23187} \mathrm{after} \mathrm{a} 120 \mathrm{~h}$ incubation with either carrier or $1 \mu \mathrm{g} / \mathrm{ml} \mathrm{CsA}$. A control blot of the stripped filter is shown below $(n=2)$. The migration of molecular mass markers is indicated 
a

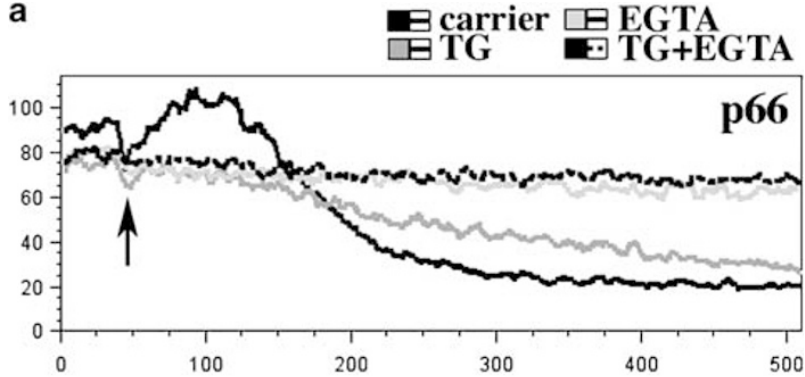

b

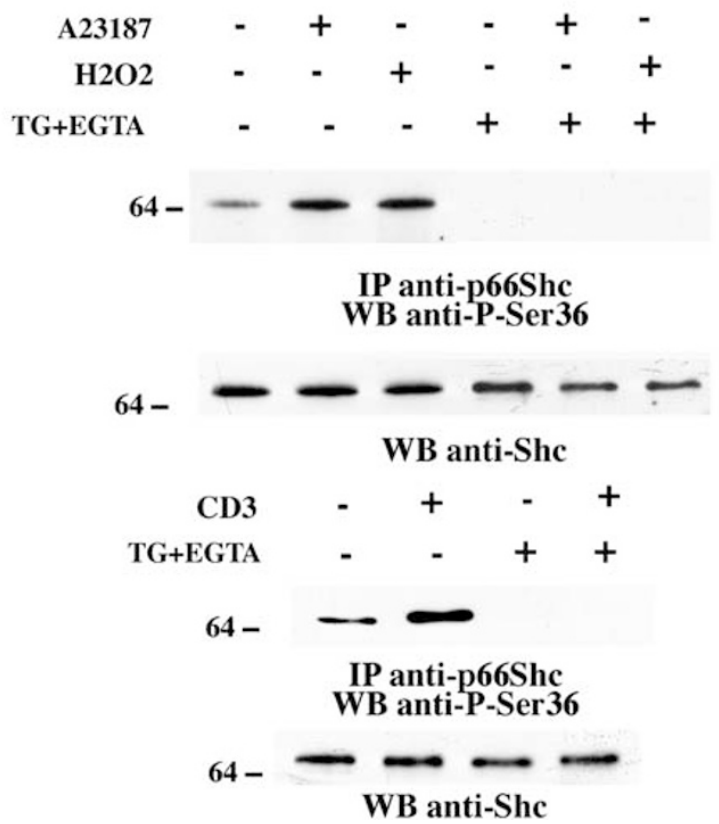

Figure 8 Serine 36 phosphorylation requires $\mathrm{Ca}^{2+}$. (a) Flow cytometric analysis of mitochondrial membrane potential in TMRM-loaded p66Shc-expressing cells treated with $500 \mathrm{ng} / \mathrm{ml}$ A23187 in the presence carrier (black line), thapsigargin $(2 \mu \mathrm{M})$ (TG, dark gray line) or EGTA (5 mM) (light gray line), alone or in combination with thapsigargin (black dashed line). The arrow indicates the time of addition of A23187. Representative experiments are shown $(n \geqslant 3)$. (b) Immunoblot analysis with a serine 36 phosphospecific antibody of p66Shc-specific immunoprecipitates from p66Shc-expressing Jurkat cells treated for $30 \mathrm{~min}$ with A23187 $(500 \mathrm{ng} / \mathrm{ml})$, $\mathrm{H}_{2} \mathrm{O}_{2}(440 \mu \mathrm{M})$ (top) or 20 min with anti-CD3 mAb (bottom). Control blots of the stripped filters are shown below

cells may further facilitate cytochrome $c$ release by favoring its dissociation from cardiolipin. ${ }^{19}$

The pharmacological evidence presented suggests that PTP opening does not play a major role in p66Shc-dependent mitochondrial membrane depolarization and triggering of the intrinsic apoptotic pathway in A23187-treated T cells. This was somewhat surprising, given that $\mathrm{A} 23187$ activates $\mathrm{CPLA}_{2}$ resulting in arachidonic acid production, ${ }^{17}$ and that p66Shc increases ROS production, ${ }^{9,10}$ events which both contribute to increase the probability of PTP opening. We cannot, however, fully exclude PTP involvement in mitochondrial depolarization, particularly in the light of the ultrastructural changes detectable after treatment with A23187. Mitochondrial cristae remodeling has indeed been observed in t-Biddependent apoptosis triggered by PTP opening. ${ }^{29}$ Furthermore, PTP opening may occur even in the presence of CsA at increasing $\mathrm{Ca}^{2+}$ loads. ${ }^{30}$
In addition to its effects on mitochondria, our data show that p66Shc impairs $\mathrm{Ca}^{2+}$ homeostasis in T cells. Although in most experiments we have exploited the amplifying effects of A23187, it should be stressed that a clear effect can be detected even under basal conditions. Indeed, higher basal levels of store-associated $\mathrm{Ca}^{2+}$ can be detected in p66Shcexpressing cells. Furthermore, these cells display increased nuclear NF-AT translocation, which is likely to cause the observed transcriptional downregulation of PMCA4a. Inhibition of calcineurin has been indeed found to suppress PMCA4 expression in neurons. ${ }^{24}$ Our demonstration that calcineurin inhibition by long-term CsA treatment restores PMCA expression strongly suggests that such a mechanism may be operational, although additional effects of CsA, such as reduction of ROS production, ${ }^{31}$ cannot be excluded. The moderate reduction in PMCA4a-specific mRNA in p66Shcexpressing cells compared to the reduction in protein suggests that PMCA1/4 expression may be controlled by additional, post-transcriptional mechanisms. PMCAs have been identified in other cell types as targets of both caspases and the $\mathrm{Ca}^{2+}$-dependent protease, calpain. ${ }^{32,33} \mathrm{Ca}^{2+}$ overload by A23187 in p66Shc-expressing cells could, however, not be rescued by pharmacological inhibition of either caspases or calpain (unpublished results), ruling out a major role of these proteases in PMCA inactivation. An alternative possibility is suggested by the finding that $\mathrm{Ca}^{2+}$ treatment of $T$ cells results in the calcineurin-dependent, CsA-sensitive upregulation of the E3 ubiquitin ligases, Cbl-b, Itch and Grail, ${ }^{34}$ that might potentially be implicated in an alternative pathway of PMCA degradation. A second effect of p66Shc expression on $\mathrm{Ca}^{2+}$ homeostasis may be mediated by its ability to promote ROS formation, ${ }^{9,10}$ leading to functional inactivation of PMCAs. ${ }^{35}$ The substantial recovery of the $\mathrm{Ca}^{2+}$-handling ability of p66Shc-expressing cells after antioxidant treatment suggests that p66Shc may also decrease the activity of PMCAs besides its effects at the transcriptional level. In this context, we cannot exclude that the reduction in PMCA1/4 expression may be overestimated, as PMCA oxidation has been shown to result in the formation of insoluble aggregates that are eventually degraded. ${ }^{36}$

Although $\mathrm{Ca}^{2+}$ overload is known to activate the intrinsic apoptosis pathway, ${ }^{19}$ the effects of p66Shc on $\mathrm{Ca}^{2+}$ homeostasis and mitochondrial function appear independent. p66Shc-expressing cells exposed to Trolox or subjected to long-term CsA treatment show indeed complete dissipation of mitochondrial transmembrane potential in response to A23187 notwithstanding normalization of the kinetics and extent of $\mathrm{Ca}^{2+}$ mobilization. Nevertheless, while the two pathways may be initially independent, they are likely to generate a feed-back amplification loop. Dissipation of the membrane potential minimizes the contribution of mitochondria to $\mathrm{Ca}^{2+}$ homeostasis and causes ATP depletion which may worsen $\mathrm{Ca}^{2+}$ overload by decreasing the fuel for the $\mathrm{Ca}^{2+}$ pumps. In turn, the alterations of $\mathrm{Ca}^{2+}$ homeostasis are likely to enhance the mitochondrial damage.

With the exception of the oxidizing activity on cytochrome $c$, all the known effects of p66Shc, including those described here, strictly require S36 phosphorylation. ${ }^{4,6,7,9}$ Interestingly, we detected a significant fraction of S36-phosphorylated p66Shc under basal conditions. In a possible scenario, the 
increased ROS production by p66Shc may cause functional PMCA impairment and increase resting $\left[\mathrm{Ca}^{2+}\right]_{\mathrm{c}}$. The resulting enhancement in calcineurin activity and NF-AT translocation would then be the initiating event leading to the decreased PMCA4a synthesis that predisposes p66Shc-expressing cells to $\mathrm{Ca}^{2+}$ overload. Furthermore, mitochondrial dysfunction might be initiated by cytochrome $c$ release due to increased Bax expression and cardiolipin peroxidation. Together, these events would synergize in sensitizing p66Shc-expressing cells to apoptosis.

\begin{abstract}
Materials and Methods
Cells, antibodies and chemicals. The cell lines used are derivatives of the Jurkat $T$ cell lymphoma line stably transfected with either empty vector or expression constructs encoding p66Shc or a p66Shc mutant carrying a serine to alanine substitution at position 36 (p66SA). ${ }^{4}$ Cell viability was measured by Trypan blue exclusion.

p66Shc/p66SA were immunoprecipitated using a rabbit polyclonal antiserum raised against a $\mathrm{CH} 2-\mathrm{GST}$ fusion protein. ${ }^{6}$ Shc was probed by immunoblot using either monoclonal (Becton-Dickinson Biosciences Italia SpA, Milan, Italy) or polyclonal (Upstate Biotechnology Inc., Boston, MA, USA) antibodies raised against the Shc SH2 domain. A mAb recognizing phosphorylated S36 was purchased from Alexis Biochemicals (San Diego, CA, USA). Anti-Erk2, anti-cytochrome $c$ and antiPMCA1/4 antibodies were from Santa Cruz Biotechnology (Santa Cruz, CA, USA); anti-Fyn antibodies from Becton-Dickinson Biosciences and anti-actin mAb from Chemicon Europe Ltd (Chandlers Ford, UK). IgG from OKT3 (anti-human CD3, ATCC) hybridoma supernatants were affinity-purified on Mabtrap (Amersham Biosciences) and titrated by flow cytometry. Fluorochrome-labeled annexin V was purchased from Becton-Dickinson Biosciences Italia SpA (Milan, Italy). Secondary unlabeled antibodies were purchased from Cappel (Durham, NC, USA), secondary peroxidase-labeled antibodies from Amersham Biosciences.

A23187, thapsigargin, CsA, aristolochic acid, MK886, indomethacin, sodium vanadate, luciferase, D-luciferin and coenzyme A were purchased from Sigma-Aldrich srl (Milan, Italy); Trolox from Merck Biosciences GmbH (Schwalbach, Germany). Sanglifherin A was generously provided by Novartis
\end{abstract} Pharmaceuticals.

Flow cytometry. Flow cytometry was carried out using a FACScan flow cytometer (Becton-Dickinson, San Jose, CA, USA) equipped with a 15-mW $488 \mathrm{~nm}$ argon ion laser. The green (FL1) and orange (FL2) fluorescences were collected through a 530/30 and a 585/42 band pass filter, respectively. Data acquisition was performed using CellQuest software. Data were analysed and plotted using Flowjo (Tree Star, Inc.).

Phosphatidylserine exposure to the cell surface was quantitated using FITClabeled annexin $\mathrm{V}$ (FL1).

$\left[\mathrm{Ca}^{2+}\right]_{\mathrm{c}}$ was measured using Fluo-4FF,AM (Molecular Probes Europe BV, Leiden, the Netherlands) (FL1). Cells ( $10 \%$ sample) were suspended in $200 \mu$ I RPMI 1640 w/o phenol Red (Invitrogen srl) added with $25 \mathrm{mM}$ Hepes pH 7.4, $5 \mu$ M Fluo-4 and $500 \mu \mathrm{M}$ sulfinpyrazone (Sigma-Aldrich srl). Cells were incubated $40 \mathrm{~min}$ at $37^{\circ} \mathrm{C}$, pelleted by centrifugation and resuspended in $1 \mathrm{ml}$ of the same medium without Fluo-4. Baseline fluorescence was recorded for $40 \mathrm{~s}$ at $37^{\circ} \mathrm{C}$. Cells were subsequently added with either A23187 $(500 \mathrm{ng} / \mathrm{ml})$, thapsigargin $(2 \mu \mathrm{M})$ or saturating amounts of anti-CD3 mAb and $50 \mu \mathrm{g} / \mathrm{ml}$ secondary antibody. Fluorescence was continously recorded for $512 \mathrm{~s}$ at $37^{\circ} \mathrm{C}$. When pharmacological inhibitors were used, carrier or inhibitor was added to the culture medium and cells were incubated at $37^{\circ} \mathrm{C}$ for the appropriate time before loading with fluo-4.

Mitochondrial membrane potential was measured using the fluorescent probe, TMRM (Molecular Probes Europe BV) (FL2). Cells (10\% $/$ sample) were suspended in $200 \mu$ l RPMl 1640 w/o phenol Red (Invitrogen srl) added with 25 mM Hepes pH 7.4 and $200 \mathrm{nM} \mathrm{TMRM}$ and incubated for $20 \mathrm{~min}$ at $37^{\circ} \mathrm{C}$. Cells were then diluted to $1 \mathrm{ml}$ with RPMI 1640 w/o phenol Red added with $25 \mathrm{mM}$ Hepes pH 7.4 and subjected to flow cytometric analysis. Pharmacological inhibitors were used as above. To induce AICD, cells were treated for $24-48 \mathrm{~h}$ with saturating amounts of plate-bound anti$\mathrm{CD} 3 \mathrm{mAb}$ as described ${ }^{4}$ and analyzed either as such or after restimulation for $6 \mathrm{~h}$. CD3 was found to be expressed at similar levels on the surface of control and p66Shc-expressing cells after the long-term treatment with anti-CD3 mAb.
Transfections and confocal microscopy. Cells were transiently transfected with the plasmid pEGFP/NFAT-1D using a modification of the DEAE/ dextran procedure, as described. ${ }^{37}$ Confocal microscopy was carried out on a Leica TCS 4D laser scanning confocal microscope equipped with an argon-krypton laser and coupled to a Leica DMRBE microscope equipped with $63 \times$ PL Apo 1.4 objectives (Leica Microsystems Heidelberg, Germany). Images collected at several focal planes were superimposed and merged into a single file using Confocal Assistant Software 4.02 (Biorad Laboratories srl, Milan, Italy) and subsequently imported into Adobe Photoshop (Adobe Systems Europe Ltd, Edinburgh, UK).

Ultrathin sections and electron microscopy. Cell pellets were fixed for $1 \mathrm{~h}$ at $4{ }^{\circ} \mathrm{C}$ in $2.5 \%$ glutaraldehyde diluted in PBS, washed in buffer overnight, and postfixed in $1 \%$ osmium tetroxide for $1 \mathrm{~h}$ at $4^{\circ} \mathrm{C}$. After one further rinse in buffer, samples were dehydrated with a graded series of ethanols and embedded in EponAraldite. Thin sections were obtained with a Reichert Ultracut II E ultramicrotome and recovered on 100 mesh copper grids. Sections were routinely stained with uranyl acetate and lead citrate and observed with a Philips CM10 transmission electron microscope with an electron accelerating voltage of $80 \mathrm{kV}$.

Immunoprecipitations, immunoblots, cell fractionations and cellular ATP measurements. Cells $\left(1-5 \times 10^{6} /\right.$ sample for direct immunoblot analysis, $1-5 \times 10^{7} /$ sample for immunoprecipitations) were lysed in $1 \%(\mathrm{v} / \mathrm{v})$ Triton $\mathrm{X}-100$ in $20 \mathrm{mM}$ Tris- $\mathrm{HCl} \mathrm{pH} 8,150 \mathrm{mM} \mathrm{NaCl}$ (in the presence of $0.2 \mathrm{mg} / \mathrm{ml} \mathrm{Na}$ orthovanadate, $1 \mu \mathrm{g} / \mathrm{ml}$ pepstatin, leupeptin and aprotinin and $10 \mathrm{mM}$ PMSF) and postnuclear supernatants were probed as such or immunoprecipitated using the appropriate polyclonal antibodies and protein-A-Sepharose (Amersham Biosciences) as described. ${ }^{4}$ Immunoblots were carried out using a chemiluminescence detection system (Pierce, Rockford, IL, USA). Immunoreactive bands were quantitated by laser densitometry (Kodak Digital Science ${ }^{\mathrm{TM}}$ Electrophoresis Documentation and Analysis System 120).

Lipid rafts were purified by density gradient centrifugation from $50 \times 10^{6} \mathrm{cells} /$ sample lysed out at $37^{\circ} \mathrm{C}$ using $1 \%$ Brij-98, and proteins from the pooled low-density raft-enriched fractions were extracted and concentrated as described. ${ }^{38}$

Post-mitochondrial supernatants were obtained by cell fractionation using a modification of the protocol described by Liang et al. ${ }^{39}$ Briefly, $30 \times 10^{6} \mathrm{cells} / \mathrm{sample}$ were washed twice with PBS, resuspended in $450 \mu$ l buffer A ( $20 \mathrm{mM}$ Hepes pH 7.0, $10 \mathrm{mM} \mathrm{KCl}, 1.5 \mathrm{mM} \mathrm{MgCl} 2,1 \mathrm{mM}$ EDTA, $1 \mathrm{mM}$ EGTA, $1 \mathrm{mM}$ DTT, $0.1 \mathrm{mM}$ PMSF, $250 \mathrm{mM}$ sucrose), incubated $10 \mathrm{~min}$ on ice and broken in a Dounce homogenizer (25 strokes). The homogenate was centrifuged at $4^{\circ} \mathrm{C}$ for $10 \mathrm{~min}$ at $600 \times \mathrm{g}$, and the supernatant was subjected to a second centrifugation at $4^{\circ} \mathrm{C}$ for $10 \mathrm{~min}$ at $700 \times \mathrm{g}$. The latter supernatant was then centrifuged at $4^{\circ} \mathrm{C}$ for $10 \mathrm{~min}$ at $7000 \times \mathrm{g}$. The pellet, enriched in mitochondria, was discarded, whereas the post-mitochondrial supernatant was used for immunoblot analysis of cytochrome $c$ release.

Cellular ATP was measured using a luciferase-based assay. Cells/sample $\left(2 \times 10^{6}\right)$ were resuspended in $40 \mu \mathrm{l} 100 \mathrm{mM}$ Tris, $4 \mathrm{mM}$ EDTA, pH 7.75 and lysed by boiling for $4 \mathrm{~min}$. Samples were centrifuged for $1 \mathrm{~min}$ at $10000 \times \mathrm{g} ; 10 \mu \mathrm{l}$ of the supernatants was added with $200 \mu$ l luciferase assay buffer $(20 \mathrm{mM}$ Tricine, $1.07 \mathrm{mM}$ $\left(\mathrm{MgCO}_{3}\right)_{4} \mathrm{Mg}(\mathrm{OH})_{2} \cdot 5 \mathrm{H}_{2} \mathrm{O}, 2.67 \mathrm{mM} \mathrm{MgSO}_{4}, 0.1 \mathrm{mM}$ EDTA, 33.3. mM DTT, $270 \mu \mathrm{M}$ coenzyme A, $470 \mu \mathrm{M}$ D-luciferin, $\mathrm{pH} 7.8$ ) and $10 \mathrm{ng}$ luciferase. Light emission was immediately recorded as relative light units using a Bioorbit 1253 luminometer.

RT-PCR. Semiquantitative RT-PCR was carried out using total RNA extracted using the RNA WIZ ${ }^{\mathrm{TM}}$ isolation reagent (Ambion Inc., Austin, TX, USA). RT-PCR was carried out using AMV reverse transcriptase and the Expand High Fidelity PCR system from Roche Diagnostics SpA (Milan, Italy). The primer for the first strand was oligo-dT (Promega Italia srl, Milan, Italy), while pairs of primers specific for human PMCA1b, $4 a$ and $4 b$ were used for cDNA amplification. Actin was used as housekeeping control. cDNA was amplified in an Eppendorf Mastercycler Thermal Cycler (Eppendorf srl, Milan, Italy). The RT-PCR products were separated by agarose gel electrophoresis, and the intensities of the PMCA and actin-specific bands was quantitated by laser densitometry. The relative levels of PMCA mRNA were normalized to the levels of actin mRNA.

Acknowledgements. We thank Sonia Grassini, Eugenio Paccagnini and Luigi Federico Falso for technical assistance; Romano Dallai for useful advice and John L. Telford for critical reading of the manuscript. This work was supported by grants from AIRC (to CTB) and the MIUR (to CTB and PB). The authors have no financial conflicts of interest. 
1. Ravichandran KS. Signaling via Shc family adapter proteins. Oncogene 2001; 20 $6322-6330$

2. Migliaccio E, Mele S, Salcini AE, Pelicci G, Lai KM, Superti-Furga G et al. Opposite effects of the p52shc/p46shc and p66shc splicing isoforms on the EGF receptor-MAP kinase-fos signalling pathway. EMBO $J$ 1997; 16: 706-716.

3. Okada S, Kao AW, Ceresa BP, Blaikie P, Margolis B, Pessin JE. The 66-kDa Shc isoform is a negative regulator of the epidermal growth factor-stimulated mitogen-activated protein kinase pathway. J Biol Chem 1997; 272: 28042-28049.

4. Pacini S, Pellegrini M, Migliaccio E, Patrussi L, Ulivieri C, Ventura A et al. p66SHC promotes apoptosis and antagonizes mitogenic signaling in T cells. Mol Cell Biol 2004; 24 1747-1757.

5. Pellegrini M, Pacini S, Baldari CT. p66SHC: the apoptotic side of Shc proteins. Apoptosis 2005; 10: 13-18.

6. Migliaccio E, Giorgio M, Mele S, Pelicci G, Reboldi P, Pandolfi PP et al. The p66shc adaptor protein controls oxidative stress response and life span in mammals. Nature 1999; 402: 309-313.

7. Smith WW, Norton DD, Gorospe M, Jiang H, Nemoto S, Holbrook NJ et al. Phosphorylation of p66Shc and forkhead proteins mediates A $\beta$ toxicity. J Cell Biol 2005; 169: 331-339.

8. Yang $\mathrm{CP}$, Horwitz SB. Taxol mediates serine phosphorylation of the $66-\mathrm{kDa}$ Shc isoform. Cancer Res 2000; 60: 5171-5178.

9. Nemoto S, Finkel T. Redox regulation of forkhead proteins through a p66shc-dependent signaling pathway. Science 2002; 295: 2450-2452.

10. Trinei M, Giorgio M, Cicalese A, Barozzi S, Ventura A, Migliaccio E et al. A p53-p66Shc signalling pathway controls intracellular redox status, levels of oxidation-damaged DNA and oxidative stress-induced apoptosis. Oncogene 2002; 21: 3872-3878.

11. Napoli C, Martin-Padura I, de Nigris F, Giorgio M, Mansueto G, Somma P et al. Deletion of the p66Shc longevity gene reduces systemic and tissue oxidative stress, vascular cell apoptosis, and early atherogenesis in mice fed a high-fat diet. Proc Natl Acad Sci USA 2003; 100: 2112-2116.

12. Zaccagnini G, Martelli F, Fasanaro P, Magenta A, Gaetano C, Di Carlo A et al p66ShcA modulates tissue response to hindlimb ischemia. Circulation 2004; 109: $2917-$ 2923.

13. Orsini F, Migliaccio E, Moroni M, Contursi C, Raker VA, Piccini D et al. The life span determinant p66Shc localizes to mitochondria where it associates with mitochondrial hea shock protein 70 and regulates trans-membrane potential. J Biol Chem 2004; 279: 25689 25695.

14. Bernardi P, Krauskopf A, Basso E, Petronilli V, Blalchy-Dyson E, Di Lisa F et al. The mitochondrial permeability transition from in vitro artifact to disease target. FEBS J 2006; 273: 2077-2099.

15. Giorgio M, Migliaccio E, Orsini F, Paolucci D, Moroni M, Contursi $C$ et al. Electron transfe between cytochrome $c$ and $\mathrm{p} 66$ (Shc) generates reactive oxygen species that trigger mitochondrial apoptosis. Cell 2005; 122: 221-223.

16. Ventura A, Luzi L, Pacini S, Baldari CT, Pelicci PG. The p66Shc longevity gene is silenced through epigenetic modifications of an alternative promoter. J Biol Chem 2002; 277: 22370-22376

17. Penzo D, Petronilli V, Angelin A, Cusa C, Colonna R, Scorrano L et al. Arachidonic acid released by phospholipase $\mathrm{A}(2)$ activation triggers $\mathrm{Ca}(2+)$-dependent apoptosis through the mitochondrial pathway. J Biol Chem 2004; 279: 25219-25225

18. Bernardi P. Mitochondrial transport of cations: channels, exchangers and permeability transition. Physiol Rev 1999; 79: 1127-1155

19. Orrenius S, Zhivotovsky B, Nicotera P. Regulation of cell death: the calcium-apoptosis link Nat Rev Mol Cell Biol 2003; 4: 552-565.
20. Scorrano L, Oakes SA, Opferman JT, Cheng EH, Sorcinelli MD, Pozzan T et al. BAX and BAK regulation of endoplasmic reticulum $\mathrm{Ca2t:}$ a control point for apoptosis. Science 2003; 300: 135-139.

21. Bautista DM, Hoth M, Lewis RS. Enhancement of calcium signalling dynamics and stability by delayed modulation of the plasma-membrane calcium-ATPase in human T cells. J Physiol 2002; 541: 877-894.

22. Chen J, McLean PA, Neel BG, Okunade G, Shull GE, Wortis HH. CD22 attenuates calcium signaling by potentiating plasma membrane calcium-ATPase activity. Nat Immunol 2004; 5: $651-657$

23. Fujimoto T. Calcium pump of the plasma membrane is localized in caveolae. $J$ Cell Biol 1993; 120: 1147-1157.

24. Guerini D, Wang X, Li L, Genazzani A, Carafoli E. Calcineurin controls the expression of isoform $4 \mathrm{Cll}$ of the plasma membrane $\mathrm{Ca}(2+)$ pump in neurons. J Biol Chem 2000; 275: 3706-3712.

25. Rao A, Luo C, Hogan PG. Transcription factors of the NFAT family: regulation and function. Annu Rev Immunol 1997; 15: 707-747.

26. Eskes R, Desagher S, Antonsson B, Martinou JC. Bid induces the oligomerization and insertion of Bax into the outer mitochondrial membrane. Mol Cell Biol 2000; 20: 929-935.

27. Gross A, Jockel J, Wei MC, Korsmeyer SJ. Enforced dimerization of BAX results in its translocation, mitochondrial dysfunction and apoptosis. EMBO J 1998; 17: 3878-3885.

28. Cai J, Jones DP. Superoxide in apoptosis. Mitochondrial generation triggered by cytochrome c loss. J Biol Chem 1998; 273: 11401-11404.

29. Scorrano L, Ashiya M, Buttle K, Weiler S, Oakes SA, Mannella CA et al. A distinct pathway remodels mitochondrial cristae and mobilizes cytochrome $c$ during apoptosis. Dev Cell 2002; 2: 55-67.

30. Soriano ME, Nicolosi L, Bernardi P. Desensitization of the permeability transition pore by cyclosporin A prevents activation of the mitochondrial apoptotic pathway and liver damage by tumor necrosis factor-alpha. J Biol Chem 2004; 279: 36803-36808.

31. Chiara MD, Bedoya F, Sobrino F. Cyclosporin A inhibits phorbol ester-induced activation of superoxide production in resident mouse peritoneal macrophages. Biochem J 1989; 264: 21-26.

32. Guerini D, Pan B, Carafoli E. Expression, purification, and characterization of isoform 1 of the plasma membrane $\mathrm{Ca}^{2+}$ pump: focus on calpain sensitivity. J Biol Chem 2003; 278: 38141-38148

33. Schwab BL, Guerini D, Didszun C, Bano D, Ferrando-May E, Fava E et al. Cleavage of plasma membrane calcium pumps by caspases: a link between apoptosis and necrosis. Cell Death Differ 2002; 9: 818-831.

34. Heissmeyer V, Macian F, Im SH, Varma R, Feske S, Venuprasad K et al. Calcineurin imposes $\mathrm{T}$ cell unresponsiveness through targeted proteolysis of signaling proteins. Nat Immunol 2004; 5: 255-265.

35. Bigelow DJ, Squier TC. Redox modulation of cellular signaling and metabolism through reversible oxidation of methionine sensors in calcium regulatory proteins. Biochim Biophys Acta 2005; 1703: 121-123

36. Zaidi A, Michaelis ML. Effects of reactive oxygen species on brain synaptic plasma membrane $\mathrm{Ca}(2+)$-ATPase. Free Radic Biol Med 1999; 27: 810-821.

37. Plyte S, Boncristiano M, Fattori E, Galvagni F, Rossi Paccani S, Majolini MB et al. Identification and characterization of a novel nuclear factor of activated T-cells-1 isoform expressed in mouse brain. J Biol Chem 2001; 276: 14350-14358.

38. Ghittoni R, Patrussi L, Pirozzi K, Pellegrini M, Lazzerini PE, Capecchi PL et al. Simvastatin inhibits T-cell activation by selectively impairing the function of Ras superfamily GTPases. FASEB J 2005; 19: 605-607.

39. Liang Y, Yan C, Nylander KD, Schor NF. Early events in Bcl-2-enhanced apoptosis. Apoptosis 2003; 8: 609-611. 